\title{
Conceptual and Connotative Meanings of Black and White Colours: Examples from Jordanian Arabic
}

\author{
Khalid Rabab'ah ${ }^{1} \&$ Emad Al-Saidat ${ }^{1}$ \\ ${ }^{1}$ University of Hail, Saudi Arabia \\ Correspondence: Emad Al-Saidat, University of Hail, Saudi Arabia. E-mail: dresaidat@gmail.com
}

Received: April 9, 2014 Accepted: May 13, 2014 Online Published: June 26, 2014

doi:10.5539/ach.v6n2p255 URL: http://dx.doi.org/10.5539/ach.v6n2p255

\begin{abstract}
This paper aims at investigating the conceptual and connotative meanings of the black and white colours as used in the Jordanian society in order to find out the role played by culture in shaping the meaning of lexical items. The results show that all the participants of the study interpret the target expressions according to their connotative meanings rather than lexical ones. The major finding of the study is white colour suggests positive meaning whereas black colour suggests negative meaning; however, few expressions do not follow this pattern such as, 'his eye is white', 'white death' and 'black horse'.
\end{abstract}

Keywords: culture, meaning, colour-words, connotation, intention, Jordanian Arabic

\section{Introduction}

Learning any language doesn't mean to master only the phonology, syntax, lexis and morphology but also to be well-informed with the basic discourse rules such as connotations, greetings, compliments, etc. (El-Hassan, 1991). The core of this study is to explain and show the various usages of connections in daily expressions containing black and white colours used in casual and social circumstances, regardless of age, gender and status.

Investigating the connotative and the associative meanings of words and expressions is an interesting field. Oxford dictionary defines connotation as an 'idea or feeling which a word invokes for a person in addition to its literal or primary meaning i.e. the associated or secondary meaning of a word or expression in addition to its explicit or primary meaning'. Words in general have meanings which are typically known as lexical entries. These lexical entries combine together with grammatical rules to form meaningful sentences (Allwood, 2003). It is well known that many words have connotations or deep meanings in addition to their lexical ones. According to Sinclair (2004), denotative meaning is classificatory and defines the place of the word in relation to other words and contexts. He states that many words have additional meanings that carry negative of positive orientations or opinions.

Some words, phrases and expressions are rich in connotations. Colour adjectives are an example of a lexical field which is very rich in connotations. Many colour connotations may be culture-and language-specific, whereas others are universal or near universal (Gage, 1999). There is a wealth of research dealing with what is called the symbolism of colours and connotations of colours. Gage (1999) explains that the difference between symbolism and connotations is that symbolism is established as a result of a clear-cut convention. For example, the black colour of clothes symbolizes mourning in many societies around the world. However, the black colour can be used with many expressions that have deep meanings or connotations such as 'black-hearted' against white-hearted'.

The difference between languages does not exist only in differences in pronunciation, vocabulary or grammar, but also in the usage of certain expressions which signals that community (Patricia, 1986). According to The World Intercultural Property Organization (WIPA) (2011), traditional cultural expressions '(i) are handed down from one generation to another, either orally or by imitation, (ii) reflect a community's cultural and social identity, (iii) consist of characteristic elements of a community's heritage, (iv) are made by 'authors unknown' and/or by communities and/or by individuals communally recognized as having the right, responsibility or permission to do so, (v) are often not created for commercial purposes, but as vehicles for religious and cultural expressions, and (vi) are constantly evolving, developing and being recreated within the community. (Report:1)'. 
Accordingly, within the same language, one might find words and expressions used by a certain group within the language community but not by other groups. Obama (2010) states that

Language is the mirror of culture, as it reflects not only real world around us, not only real life conditions, events, and experiences, but also a public conscience and self-conscience of the nation, mentality, national character, way of life, customs and traditions, habits, moral, system of values, vision, world outlook, and world perception.

According to Guimei (2009), different cultures have different expressions using colours in general. The connotative or associative meanings are different from one culture to another. For example, white colour in the Chinese culture shows the Chinese's material and spirit disgust. It is also a symbol of death, lifeless performance and bad omen. In the Arab World white colour carries purity of heart and happiness which is the opposite in the Chinese culture.

There are many words, phrases and expressions of different colours in Arabic. Colours may convey different messages to people of different cultures. This paper mainly is concerned with the deepen connotations of the black and white colours in Jordanian Arabic definitely in Irbid city.

\section{Background of the Study}

There is no doubt that the relationship between language and culture is deep and undeniable. Evans (2006) points to this relationship and uses of the expressions 'culture-specific lexical concepts' to refer to words and expressions which cannot be understood by language learners of other culture. He also states that culture is shared and maintained through the use of language. Culture is also reflected in language and language is reflected in culture. For example, Jordanians can easily figure out the associative meaning that the white colour carries in this expression (his/her eye is white) which means that the person is rude or shameless; however, in other cultures, this might not be the same or others might not be able to get the connotation meaning of the white eye.

According to Xing (2008) and Tao (1994), among all the colour terms in all world languages, white and black have the longest history, and this is also true in Arabic culture, because they are the most contrastive and easily identified colours such as white-hearted vs. black-hearted or a white future vs. a black future.

Jordan is an Arab Muslim country situated in the Middle East. In Jordan as well as all other Arab countries, people's first language is Arabic. However, a sort of variations can be found among these countries, this is why in linguistic studies scholars refer to regional varieties, such as, Jordanian Arabic, Saudi Arabic, Syrian Arabic, etc. Our data were taken from Irbid - a city in north Jordan. The usage of black and white colours in this area (and many other colours) is distinguishable. Colours in general and black and white in particular are used to describe human emotions, behaviours and some aspects of personal characteristics. Still, the lexical and connotative meanings of colours lack a systematic study emphasizing the connotative or associative meaning and its relation to the lexicalized meaning and culture.

As mentioned above, the subjects of the study are Jordanians. Being Muslims, the Jordanian society is deeply influenced by the Islamic culture. The Holy Quran is the book of Allah that was sent to Prophet Muhammad (PBUH). Therefore, there is no doubt that the words and expressions used in this book are highly acceptable for Arab Muslims. The Holy Quran mentions many colours but, as far as the topic of this study is concerned, black and white colours are used connotatively in the following two verses:

"On the Day when some faces will be (lit up with) white, and some faces will be (in the gloom of) black: to those whose faces will be black, (will be said):'Did ye reject faith after accepting it?' Taste then the penalty for rejecting faith" (Q 3:106).

The Quran also says:

"But those faces will be (lit with) white, they will be in (the light of) Allah's mercy; therein to dwell forever" (Q $3: 107)$.

These two verses show the opposite meaning of black and white. The winners of Allah's mercy have white faces because of happiness and delight. The losers of Allah's mercy have black faces because of sins, shame, and bad deeds.

Thus, from a religious perspective, black refers to negative meanings such as, sins, scandals, bad deeds and impurity. The white colour refers to positive meanings including innocence, purity, and good deeds. Moreover, the dress of pilgrims is white which indicates getting rid of sins and evil; therefore, Muslims wear special white dress during their pilgrimage (the Muslims' religious journey to Mecca in KSA). These examples are obvious evidence about the strong impact of the Islamic culture on Arab Muslims' usage of black and white colours in 
their lives. Moreover, in the Pre-Islamic Arabic literature there is evidence that these two colours were used connotatively; Btoosh (forthcoming) conducts a study to explore the colour connotations in Antara's poetry, a pre-Islamic poet and hero. He argues that much of the message of colour in Antara's work goes beyond the natural meaning, and much of the colour story has not been revealed yet. The results of the study show that Antara competently and deliberately uses colour in an attempt to mitigate the negative connotations adhered to 'blackness' by connecting it to precious values, immortality, elegance, eternity and strength. On the other hand, Antara undervalues the widespread social values associated with 'whiteness' by using it in contexts where blackness prevails over whiteness.

With reference to Jordanian Arabic, Al-Adaileh (2012) studies the connotative meanings of black, white and other colours in the Jordanian society. His study shows that in Jordanian Arabic all colours have euphemistic and dysphemistic connotations, but, as far as back and white colours are concerned, black is found to be predominantly dysphemistic and attached with negative connotations whereas white is used euphemistically and mostly has positive connotations.

\section{Subjects and Methodology}

The subjects of this study are native speakers of Jordanian Arabic. All are from Irbid city. 100 subjects aged 20 60 participated in this study. Sex and educational level were ignored since the study deals with cultural-bound expressions. Each participant was given 31 expressions and asked to give the meaning as s/he perceived. The questionnaire was carried out in an informal way to receive natural and spontaneous answers. After getting the questionnaires ready, the researchers transcribed the expressions using IPA symbols. However, the following symbols are used to represent certain Arabic sounds that do not match IPA symbols:

/ț/ voiceless dental emphatic stop

/d/ voiced dental emphatic stop

/ș/ voiceless alveolar emphatic fricative

/ż/ voiced alveolar emphatic fricative

/ $\mathrm{x} /$ voiceless velar fricative

$/ \dot{\mathrm{g}} /$ voiced velar fricative

$/ \hbar /$ voiceless pharyngeal fricative

/ç/ voiced pharyngeal fricative

/q/ voiceless uvular stop

\subsection{Limitations of the Study}

This work is limited in its scope and aim. It covers only white and black colours although other colours can be involved in the study. There is a limitation in the subjects of the study because it is assumed that these are cultural expressions and the number would not matter.

\section{Data and Discussion}

This section presents some of the cultural expressions connected to black or white colours in Irbid city, Jordan; however, some of these expressions are used all over Jordan and in other Arab countries as well. This section will also show the literal translation to clarify the lexical meaning of each expression. It is worth mentioning that in Arabic language the third person singular is used as a default pronoun. It is like suffixes in English, it is added to the end of the word. For example, /galb/ 'heart', /galbu/ 'his heart'. For female, we say /galbha/ 'her heart'. This means $\{-\mathrm{u}\}$ stands for 'his' and $\{-\mathrm{ha}\}$ for 'her'. For plural we add $\{-$ na $\}$ as in /wdzu:hna/ 'our faces'.

Arab people associate a wide range of meanings to white and black colour terms because they are the most contrastive and identified among all colour terms. For this reason, the word white means good in white-hearted and white future, and the word black means bad in black-hearted and black future. This is true not only in Arabic culture but also in all world languages. According to Xing (2008), Baxter (1983), and Tao (1994) these two words are prominent in the history of colours.

\subsection{White}

Houghton (2007) states that the white colour symbolizes nature. Therefore, this is the reason why it is associated with clouds, cotton, crystal, and air. White, which means clear, clean, and pure is viewed positively in Arabic language in general and in Jordanian Arabic in particular as it indicates innocent, harmless, and evil-free matters. With this positive assumption, if something is white, it is not stained and therefore clean. So, if a person has a 
clear or pure mind, this person has a clear tolerance of matters.

In this sense, /galbu Rabjaż/ 'his heart is white' symbolizes a person who has no harm or evil in his/her heart toward others. It also describes a person who is known for love and not hiding any evil feelings toward others; therefore, if someone has been told $\mathrm{s} /$ he has a white heart, then it is a great compliment (Al-Adaileh, 2012). Similarly, the expression /wadzhu ?abjaż/ 'his face is white' indicates that the person who is talked about is honest and has never done bad or shameful deeds. It is used generally to describe people who are in wealth and good health or youthful (blooming). Another expression that combines the word 'white' with face is /bajja ż wdzuhna/ 'to make our faces white' which symbolizes good achievements and deeds as when a person became a credit for his family because he achieves something great or distinguished that makes others feel proud of him i.e., it used to thank a person who has helped in getting you out of a difficult problem. In this connection, a helpful or generous person is described as Rr:du berża/ his hand is white because he helps people in overcoming their problems, such as to find a job for someone. Trying to help other people is also indicated by the use of /nijjtu beiża/ 'his intention is white' which refers to a person whose is honest and tries sincerely to help other people. However, it associates the meaning of having no harm or evil in a person's intention and not hiding any evil or harmful intentions toward others.

Deeds in one's life are also indicated by the use of the expression / façruu Pabjaż/ 'his hair is white' to positively describe a person who is wise and has a vast, good experience. On the other hand, it has a negative meaning when describing a person who is tired or has faced a lot of problems and difficulties in his life. Another expression used positively to describe one's good deeds and record in the past is /șafhtu berża/ 'his page is white'. People use this expression to describe a respected person with a good past record and has not done mistakes, sins, scandals or shameful deeds, i.e. a person who has a good reputation.

The expression /çeınu beıża/ 'his eye is white' implies a negative meaning by the Jordanian participants of this study. This expression is used to describe a person who is notorious, known for his shameful deeds, rude, and one who might do something which is generally considered unacceptable by the members of the society. However, Al-Adaileh (2012) finds this true in his investigation of the connotations of the Arabic colour terms in the Jordanian Arabic. He states that when the speaker refers to a woman using this expression; the one being described is disrespectful of others and a rude female who has a strong personality more than is required; thus, a negative meaning is associated in this case. On the contrary, he notices that this expression is used euphemistically in Jordanian Arabic, more precisely south Jordan dialects, to politely describe a person who lost sight as the whiteness of eyes indicates sight loss; thus, a positive meaning is associated. In line with Al-Adaileh (2012) positive meaning, Hasan (2011) find the same meaning in a study meant to contrast the two colours in question in English and Arabic.

In Jordanian Arabic the expression /jJ:m Rabjaż/ 'a white day' is used to positively describe a day that has an event or events which are memorable, unforgettable or exquisite. Such expression might be borrowed from the Egyptians who work in Jordan as result of influencing the local community. In Egypt, the same expression is found frequent /ja nha:r Pabjađ/ 'what a white day!' in reaction to good news (Al-Adaileh, 2012).

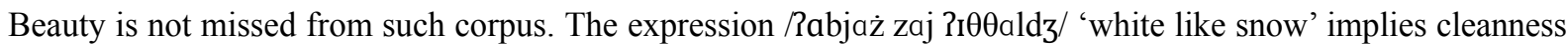
such as when someone says this girl is white like snow to mean that her skin is white and clean, thus, symbolizing beauty. In a similar way, the expression /hama:ma beiża/ 'a white pigeon' describes a person especially a female to say that he is very beautiful. However, it is refers to a messenger bearing good news. In the Arabic culture, to see a white pigeon has a good omen of getting good news and a happy future (Hasan, 2011).

Certain expressions are used to make prediction about the future of people either because of what they are engaged in at present or as a piece of advice. For instance, /mustaqbalu Rabjaż/ 'his future is white' indicates bright coming days full of good chances; thus, a person whose future is white has good opportunities and chances in the proximate future. Another example is /bida:ja berża/ 'a white beginning' meaning a bright, distinguished beginning which indicates happy outcomes. The word white appears in some Arabic proverbs. As far as the Jordanian context is concerned, /gIr labjaż/ 'a white piaster' is taken from the proverb 'save your white piaster to your black day' meaning that the money you save can be used in hard days. Thus, it is however similar to the English 'a penny saved is a penny gained'.

/kıðbrh beiża/ 'a white lie' is an expression used to describe an unintentional lie making no harm or a big problem to the involved person; such lies do not mean to make conflict between people; instead, they save relationships between people and in certain cases solve problems.

According to the data of the present study, the expression /mo:t Rabjaż/ 'white death' is not common in the daily 
speech of the target society. It means sudden death: death that comes unexpectedly or with no obvious illness or after a short period of illness lasting few minutes or hours (see also, Hasan, 2011 and Al-Adaileh, 2012).

\subsection{Black}

The colour 'black' has a more negative meaning than other colours do in most languages; Jordanian Arabic is no exception. Allan (2007) states that it is the most negatively used colour among all colours, as far as its connotations are concerned. Thus, it is associated with mischievous, dirty, unseen and strong magic, bad luck, bad end, enemies with strong hostility, and evil issues in general. However, according to Allan (2007), in western communities the term 'black' is associated with funereal clothes and other materials related to death. Such negative connotations can be explained by the lack of light and the transparency of darkness in this colour (Houghton, 2007; Salah, 2006).

In Jordanian Arabic, different body parts of people are described black to indicate the negative characteristics of the person being talked about. For instance, /galbu ?aswad/ 'his heart is black' describes a person who is cruel, hates other people, and wishes them bad and misery deeds - a person who is full of hatred. 'Black' is associated with 'face' in /widzhu ?aswad/ 'his face is black' to describe people who are dishonest and have done a lot of bad or shameful deeds. They are ashamed from others and cannot confront other people because of their deeds which are usually scandalous. On the other hand, as evident from the data, this expression is used to describe innocent people who are tired, worried or depressed. A related expression, /sawwad wdzu:hna/ 'makes our faces black', is found to be used in the Jordanian society which refers negatively to people who, because of their bad deeds, ashamed their family and relatives among other people in the society.

To give the listener a swift idea about someone's history, Jordanians tend to combine the term 'black' with different nouns to describe the bad records of a person; thus, the expression /qa:?rma so:da/ 'a black list' describes a person who is considered untrustworthy, disloyal and appeared in court for their illegal deeds; /șafhtu $\mathrm{sJ}: \mathrm{da} /$ 'his page is black' indicates that this person has a very bad records and has done a lot of sins, scandals and shameful deeds. Another expression related to people's history is /ta:rr:x laswad/ 'black history' which describes a history rich in bad deeds, sins and scandals. Similarly, /nugța so:da/ 'a black spot' describes a bad event in a person's history that is unforgettable.

People's hidden agendas and luck are described by /nijjtu so:da/ 'his intention is black' which means that the person being described hides evil intentions toward others, although they might act nicely in front of others and show kindness. /haż laswad/ 'black luck' describes a person whose luck is very bad and faces a lot of difficulties or problems in their life. Moreover, present and future times are described by the use of the term 'black', for instance, the expression /j3:m ?aswad/ 'a black day' designates a day which is full of problems or bad events such as when a person loses something or somebody that causes him a lot of pain and hard time. This expression is also used in other Arab countries such as Egypt where people use /ja nha:r ?iswid/ 'what a black day!' to describe a similar situation of /jJ:m ?aswad/. As for the future, the expression /mustaqbal ?aswad/ 'black future' is used to predict the future life especially when someone predicts events full of difficulties and problems that might happen in the future. In the same line, the expression /bida:ja so:da/ 'a black beginning' is used to describe a failed beginning especially when someone begins something improperly with many mistakes.

The bearer of bad news is described as /ġerma sJ:da/ 'a black cloud' or /gura:b ?aswad/ 'a black crow' with no difference in meaning but the latter is more common as evident from the data collected. However, in the Jordanian society in general the presence of a crow signals a bad omen.

It is not always true that 'black' implies negative attitudes and characteristics. In the data available, one expression is found to have a positive rather than a negative meaning. The expression /hșa:n laswad/ 'a black horse' is used to describe a person who is very strong, hard-working and tireless, thus, a positive meaning.

\section{Conclusion}

The connotative meaning is the dominant in all of the expressions that we explained in this study. None of the expressions is interpreted according to its lexical meaning alone. In addition, the cultural impact is obvious in such usages; expressions used by a certain group within the language community but not by another group. Generally, social beliefs and ideas are reflected in the connotative interpretation of those expressions. The lexical meaning is present as the anchoring point to the connotative meaning although the connotative meaning is the dominant one.

We notice that the first eight expressions from the two groups have the opposite meaning in both the lexical and connotative meaning. Most of expressions associated with the white colour suggest positive meaning. However, few expressions suggest negative meanings such as /çernu beiża/ 'his eye is white' and /mə:t Rabjaż/ 'white 
death'. Whereas, most of expressions associated with the black colour suggest negative meanings. However, few expressions suggest positive meanings such as /hșa:n Raswad/' a black horse'. Some expressions have more than

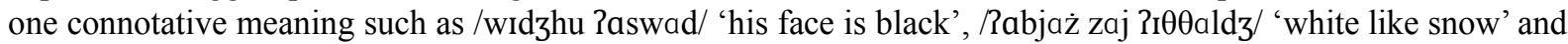
/hama:ma beiża/ 'a white pigeon'. / Jaçruu Rabjaż/ 'his hair is white' is the only expression which suggests negative and positive meaning and at the same time depends on the context.

Jordanians often use those expressions instead of using adjectives directly. For example, instead of saying he/she is a bad person they say /șafhtu so:da/ 'his page is black' or instead of saying he/she is rude they say /çernu berża / 'his eye is white'. As clear from the above discussion, linguistic meaning and cultural meaning are inseparable. Therefore, to acquire a language, one has to acquire the culture of its native speakers too.

\section{References}

Al-Adaileh, B. (2012). The Connotations of Arabic Colour Terms. Linguistica. Retrieved from http://www.phil.muni.cz/linguistica/art/al-adaileh/ada-001

Allan, Keith. 2007. The Pragmatics of Connotation. Journal of Pragmatics, 39(6), 1047-1057. http://dx.doi.org /10.1016/j.pragma.2006.08.004

Allwood, J. (2003). Meaning Potentials and Context: Some Consequences for the Analysis of Variation in Meaning. In H. Cuyckens, R. Dirven, \& J. Taylor (Eds.), Cognitive Approaches to Lexical Semantics. Berlin/New York: Mouton de Gruyter, 29-66. http://dx.doi.org/10.1515/9783110219074.29

Baxter, W. (1983). A Look at the History of Chinese Colour Terminology. Journal of Chinese Language Teachers.

Btoosh, M. (forthcoming). The Pragmatics of Color in Antara's Poetry.

El-Hassan, S. (1991). Linguistic Etiquette at Jordanian Shops. Mu'tah Journal for Research and Studies, 6(1), 31-49.

Evans, V. (2006). Lexical Concepts, Cognitive Models and Meaning-Construction. Cognitive Linguistics, 17(4), 491-534. http://dx.doi.org/10.1515/COG.2006.016

Gage, J. (1999). Color and Meaning: Art, Science and Symbolism. Thames and Hudson: Singapore.

Guimei, H. (2009). English and Chinese Cultural Connotation of Color Words in Comparison. Asian Social Science, 5(7), 160-163.

Hasan, A., Al-Sammerai, N., \& Bin Abdul Kadir, F. (2011). How Colours are Semantically Construed in the Arabic and English Culture: A Comparative Study. English Language Teaching, 4(3), 206-213. http://dx.doi.org/10.5539/elt.v4n3p206

Houghton, M. (2007). The American Heritage Dictionary of the English Language (4th ed.).

Obama. (2010). Retrieved from http://voices.yahoo.com/language-culture- 5185683.html

Patricia, C. (1986). The Acquisition of Communicative Style in Japanese. In B. Schieffelin, \& E. Ochs (Eds.), Language Socialization across Cultures. Cambridge: Cambridge University Press.

Salah, S. A. (2006). Connotation and Cross Cultural Semantics. Translation Journal, 10(4).

Sinclair, J. (2004). Trust the Text: Language, Corpus and Discourse. London \& New York: Routledge.

Tao, W. (1994). Colour Terms in Shang Oracle Bone Inscriptions. Bulletin of the School of Oriental and African Languages 59(1), 63-101. http://dx.doi.org/10.1017/S0041977X00028561

The World Intellectual Property Organization (WIPO). (2011). Intellectual Property and Traditional Cultural Expressions/Folklore. Retrieved from May 2, 2012, http://wo.ala.org/tce/faq/

Xing, J. Z. (2008). Semantics and Pragmatics of Colour Terms in Chinese. Washington: Western Washington University.

\section{Copyrights}

Copyright for this article is retained by the author(s), with first publication rights granted to the journal.

This is an open-access article distributed under the terms and conditions of the Creative Commons Attribution license (http://creativecommons.org/licenses/by/3.0/). 